Document downloaded from:

http://hdl.handle.net/10251/50788

This paper must be cited as:

Benamghar, A.; Gómez-Hernández, JJ. (2014). Factorial kriging of a geochemical dataset for the heavy-metal spatial-pattern characterization The Wallonian Region. Environmental Earth Sciences. 71(7):3161-3170. doi:10.1007/s12665-013-2704-5.

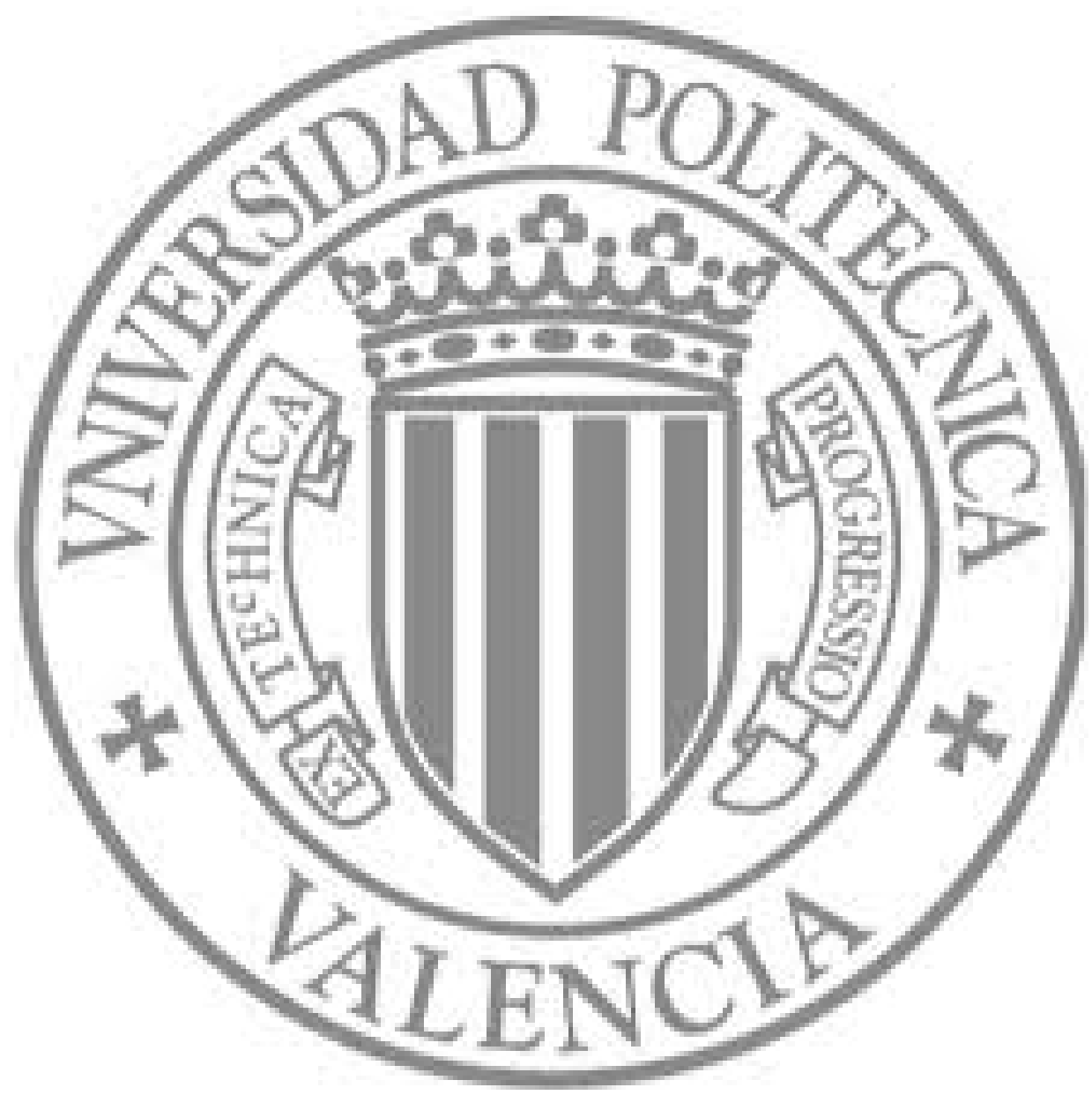

The final publication is available at

http://dx.doi.org/ 10.1007/s12665-013-2704-5

Copyright Springer Verlag (Germany) 


\title{
Factorial kriging of a geochemical dataset for the heavy-metal spatial-pattern characterization
}

\section{The Wallonia Region}

\author{
Ahcène Benamghar • J. Jaime \\ Gómez-Hernández
}

Received: date / Accepted: date

\begin{abstract}
Characterizing the spatial patterns of variability is a fundamental aspect when investigating the origin of the spreading of a multivariate phenomenon. In this paper, a large multivariate dataset from the southeast of Belgium has been analyzed using factorial kriging. The purpose of the study was to explore and retrieve possible scales of spatial variability of heavy metals. This is achieved by decomposing the variance-covariance matrix of the multivariate sample into coregionalization matrices, which are, in turn, decomposed into transformation matrices, which serve to decompose each regionalized variable as a sum of independent factors. Then, factorial cokriging produces maps of the principal factors, which can be compared with the underlying lithology. This comparison identified a few point scale concentrations, which may reflect anthropogenic contamination, it also identified local and regional scale anomalies clearly corresponding to known mineralizations and underlying geology. The results from this analysis could serve to guide the authorities in locating those areas which need remediation.
\end{abstract}

Keywords Factorial kriging analysis - Geostatistics · Coregionalization · Heavy metal contamination · Wallonia geochemical data set · Belgium

\section{Introduction}

Quantifying spatial patterns of variability of soil properties is an important issue in earth science and it becomes more important in the study of contaminated soils. Depending on the nature and characteristics of the contamination source, different spatial ranges of influence exist: point, local and regional (Xiao et al. 2010, Candeias et al. 2011, da Silva et al. 2013, Huang et al. 2013 and Krishna et

\footnotetext{
A. Benamghar

ENSTP, 01, Rue Garidi Kouba Alger Algeria

E-mail: a.benamghar@gmail.com

J. Jaime Gómez-Hernández

Research Institute of Water and Environmental Engineering,

Universitat Politècnica de València, Spain

E-mail: jgomez@upv.es
} 
al. 2013). For example, a geochemical halo around an ore body usually has a large spread and is more likely to be observed at a regional scale, while contamination resulting from a small mineralized vein or industrial wastes do not spread much and would be observed only locally, or as a point signal.

These contaminations of different scale origin will manifest in nature as a complex signal. The analysis and interpretation of this complex signal is difficult and requires its decomposition into the different spatial components. Traditionally multivariate datasets are analyzed with statistical methods, such as principal component analysis or correspondence analysis. For example, recent works like Rodriguez Martn et al. (2007), Guagliardi et al. (2013), Candeias et al. (2011), Maria Astel et al. (2011), da Silva et al. (2013), Khedhiri et al. (2011), Liebens et al. (2012) and Huang et al. (2013) have discussed relevant case studies but showed limitations as the focus was on the multivariate aspect of the problem and did not account for the possible existence of the spatial components mentioned above. Geostatistical factorial kriging analysis (FKA) was introduced as an alternative in the early 80's by Matheron (1982) and has been discussed thoroughly by Wackernagel (1988, 1989) and Goovaerts $(1991,1992,1997,1998)$ among others. After its introduction, we can easily notice an increasing use of FKA, mainly, but not limited, to geochemical data analysis to identify spatial patterns of soil contamination (Yeh et al. 2006, Queiros et al. 2008 and Guagliardi et al. 2013).

\section{Materials and methods}

\subsection{Wallonia data set}

In the early 80's, 10000 stream sediment samples were taken in the Wallonian region. As reported by Sondag et al. (1984), the samples were collected along the streams using a soil auger at the intersection of the lower edge of the bank and the live bed, in flapping water area. Sampling density was approximately uniform at 1 sample per square kilometer (Sontag et al., 1984). All samples were analyzed for 20 geochemical elements, including many heavy metals. This study uses directly the database generated at the time, focusing in the analysis of heavy metals in the eastern part of the Wallonian region (Fig. 1), shortly referred to as ESM (for "Entre-Sambre-et-Meuse" in French). This part of Belgium contains 1765 samples of the Wallonia data set. Table 1 displays descriptive statistics of the data set for the elements of interest.

A decree adopted in the early 90's demanded heavy and expensive remedial actions when healthy limits of the heavy metal concentrations were surpassed. However, if it could be proven that the contaminant concentrations had a natural origin then no remediation was required. Therefore, it is very important to establish whether contamination is of natural or human origin. Factorial kriging could be used to distinguish scales of variability underlying the spatial distribution of heavy metal concentrations; presumably, those contaminants relevant at the point scale would be anthropogenic, whereas those with a regional scale would be natural. Wallonia experienced in the past a dynamic mineral industry, and the region is well known for its numerous mineralizations. The ESM geology, for instance, is dominated by Palaeozoic silicated formations intersected by east-west parallel bands of Frasnian and Devonian carbonates with several spreading metal mineralizations 
Table 1 Descriptive statistics of the ESM data set (values in ppm, except Fe in \%).

\begin{tabular}{||l|c|c|c|c|c|c|c|c|}
\hline STATS & Zn & Pb & Cu & Sr & Ba & La & Y & Fe \\
\hline Nbr & 1766 & 1765 & 1765 & 1769 & 1768 & 1769 & 1769 & 1769 \\
Min & 13 & 1 & 1 & 1 & 39 & 1 & 1 & 0.19 \\
Max & 860 & 567 & 133 & 346 & 744 & 33 & 39 & 24.6 \\
Median & 79 & 23 & 16 & 42 & 313 & 4 & 1 & 2.93 \\
Mean & 92.50 & 30.52 & 18.11 & 46.45 & 313.18 & 5.23 & 2.94 & 3.37 \\
stand-dev & 60.34 & 35.41 & 10.16 & 25.16 & 73.30 & 4.52 & 3.51 & 1.98 \\
Variance & 3640 & 1254 & 103 & 633 & 5373 & 20.40 & 12.36 & 3.92 \\
C.V.(\%) & 0.65 & 1.16 & 0.56 & 0.54 & 0.23 & 0.86 & 1.19 & 0.59 \\
Asymmetry & 4.12 & 7.12 & 2.95 & 2.88 & 0.51 & 1.53 & 3.98 & 3.89 \\
Kurtosis & 29.92 & 77.10 & 19.22 & 18.41 & 2.56 & 3.40 & 25.15 & 26.61 \\
\hline
\end{tabular}
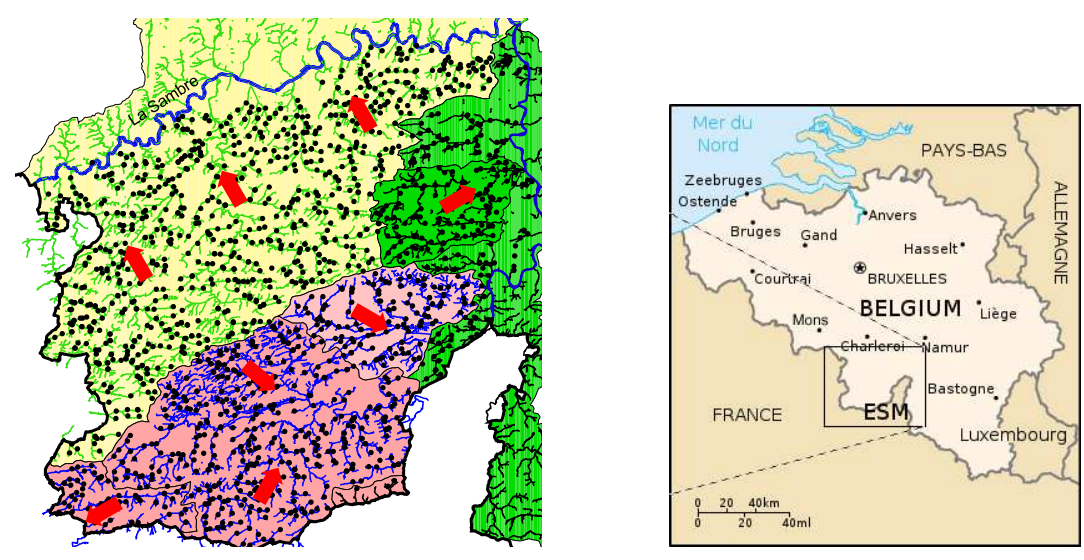

Fig. 1 ESM area geographical situation and sample distribution.

\subsection{Factorial kriging - Theory}

Here we present a quick review of factorial kriging analysis as applied to a multivariate data set. The reader interested in a deeper understanding of the theoretical and implementation details of the method is referred to the paper by Goovaerts (1992). Multivariate data sets are usually analyzed using statistical methods such as factorial analysis (FA) in order to show existing associations of variables and the relations among them. However, this approach does not explore the potential spatial correlations of the variables. When two or more variables show a spatial correlation (either at the point, local or regional scale) they are said to be coregionalized. Factorial kriging analysis (FKA) is a geostatistical method intended to explain the reasons underlying the spatial variability of a multivariate set of coregionalized variables. The FKA technique, which was first presented by Matheron (1982), is based on the assumption that the nested structures needed to fit the simple and cross-variograms of the variables relate to the scales that control their spatial correlations. The linear model of coregionalization (LMC) (Goovaerts, 1993) is adopted to fit the simple and cross semi-variograms and to establish the common underlying spatial structures of the multivariate set. Usually, three spatial scales can be observed: point, local and regional. 
Authors like Wackernagel (1989) have interpreted the point component as part of the signal corresponding to a scale below the size of the sampling mesh. The local component is seen as a small size scale, like the medium diameter of a geochemical dispersion halo. And finally, the regional component is viewed as the large scale of the geochemical signal.

\subsection{Multivariate geostatistical model}

Suppose that $p$ variables $\left(\left\{z_{i}(x) ; i=1, \ldots, p\right\}\right)$ have all been sampled at the same $n$ locations $(\alpha=1, \ldots, n)$. These samples can be interpreted as a realization of a set of $p$ correlated random functions $\left\{Z_{i}(x) ; i=1, \ldots, p\right\}$. The set of $n \times p$ observations is noted $\left\{z_{i}\left(x_{\alpha}\right) ; i=1, \ldots, p ; \alpha=1, \ldots, n\right\}$.

The spatial structure and correlations among the different variables can be characterized by the simple $\gamma_{i i}(h)$ and cross semi-variograms $\gamma_{i j}(h)$, which can be assembled in a symmetric matrix $\boldsymbol{\Gamma}(h)$ :

$$
\boldsymbol{\Gamma}(h)=\left(\begin{array}{ccc}
\gamma_{11}(h) & \ldots & \gamma_{1 p}(h) \\
\cdot & & \cdot \\
\cdot & & \cdot \\
\gamma_{p 1}(h) & \ldots & \gamma_{p p}(h)
\end{array}\right)
$$

To ensure that the variance of any linear combination of the random functions is not negative, the matrix $\boldsymbol{\Gamma}(h)$ must be conditionally negative semi-definite. This means that the functions used to model the variograms and semi-variograms must meet certain restrictions. A sufficient set of restrictions are those given by the linear model of coregionalization, which is used in this work.

\subsection{The linear model of coregionalization}

Under the linear model of coregionalization (LMC), it is assumed that each semivariogram and cross semi-variogram function $\gamma(h)$ can be decomposed into a linear weighted sum of the same basic functions $g(h)$, each one related to a spatial scale. This decomposition can be written in matrix form as:

$$
\boldsymbol{\Gamma}(h)=\mathbf{B}_{0} g_{0}(h)+\mathbf{B}_{1} g_{1}(h)+\ldots+\mathbf{B}_{S} g_{S}(h)=\sum_{u=1}^{N_{S}} \mathbf{B}_{u} g_{u}(h)
$$

where $N_{S}$ is the number of basic functions, $g_{u}(h)$ are the basic functions (each one representative of a different spatial scale), and $\mathbf{B}_{u}$ are the coregionalization matrices.

The matrices $\mathbf{B}_{u}$ capture the multivariate structure at the different spatial scales. The global variance-covariance matrix $\mathbf{V}$ is the sum of the coregionalization matrices $\mathbf{V}=\mathbf{B}_{0}+\mathbf{B}_{1}+\ldots+\mathbf{B}_{S}$. In the limit, for large $h, \boldsymbol{\Gamma}(h)$ tends towards $\mathbf{V}$ and variables become uncorrelated. This relationship between the global covariance matrix and the coregionalization matrices indicates that $\mathbf{V}$ is a mixture of the correlation structures found at different spatial scales. 
The condition of negative semi-definiteness of $\boldsymbol{\Gamma}(h)$ is satisfied if each $g_{u}(h)$ function is negative semi-definite and if each matrix $\mathbf{B}_{u}$ is positive semi-definite (Wackernagel, 1992):

$$
b_{i i}^{u} \geq 0 \quad \forall i, u \quad \text { and } \quad\left|b_{i j}^{u}\right| \leq \sqrt{b_{i i}^{u} b_{j j}^{u}} \quad \forall i, j, u
$$

The linear model of coregionalization described by Eq. (2) assumes that each of the $p$ random functions $\left\{Z_{i}(x) ; i=1, \ldots, p\right\}$ can be decomposed into a set of orthogonal random functions $\left\{Y_{v}^{u}(x) ; v=1, \ldots, p ; u=1, \ldots, N_{S}\right\}$ :

$$
Z_{i}(x)=\sum_{u=1}^{N_{S}} \sum_{v=1}^{p} a_{i v}^{u} Y_{v}^{u}(x)
$$

where $a_{i v}^{u}$ are the transformation coefficients. For an index $u$, the functions $Y_{v}^{u}(x)$, called regionalized factors, have as variograms the basic functions $g_{u}(h)$ in Eq. (2). Eq. (4) can be rewritten in matrix notation as:

$$
\mathbf{Z}(x)=\sum_{u=1}^{N_{S}} \mathbf{Z}_{u}(x)
$$

with

$$
\mathbf{Z}_{u}(x)=\mathbf{Y}_{u}(x)\left(\mathbf{A}_{u}\right)^{T}
$$

The components $\mathbf{Z}_{u}(x)$ of $\mathbf{Z}(x)$ are called the spatial components, since they represent the behavior of the random function at each scale $u$, and their variancecovariance matrix is given by the coregionalization matrix $\mathbf{B}_{u}$.

Since the regionalized factors $Y_{v}^{u}(x)$ are orthogonal, each matrix $\mathbf{A}_{u}$ can be obtained by a factorial decomposition of the coregionalization matrix $\mathbf{B}_{u}$ (Wackernagel, 1988):

$$
\mathbf{B}_{u}=\mathbf{A}_{u}\left(\mathbf{A}_{u}\right)^{T}
$$

The transformation coefficients in $\mathbf{A}_{u}$, correspond to the covariances between the regionalized factors $Y_{v}^{u}(x)$ and the spatial components $Z_{i}^{u}(x)$. The correlation between the regionalized factors and the spatial components can be determined by the expression:

$$
r_{i j}^{u}=\frac{a_{i j}^{u}}{\sqrt{a_{i i}^{u} a_{j j}^{u}}}
$$

- Cartography of the multivariate spatial information: Three kinds of information can be mapped to illustrate the behavior of the variables and their relationships at different spatial scales (Wackernagel, 1988):

(i)- The regionalized variables themselves, $Z_{i}(x)$;

(ii)- The spatial components $Z_{i}^{u}(x)$ of the regionalized variables at spatial scale $u$;

(iii)- The factors $Y_{v}^{u}(x)$, which show essential information of a given spatial scale for each variable. 
We have chosen to analyze the factors. Each factor will be estimated at point $x_{0}$ by cokriging the $n$ closest values of the $p$ variables around $x_{0}$ :

$$
Y_{v}^{u *}\left(x_{0}\right)=\sum_{i=1}^{p} \sum_{\alpha=1}^{n} \lambda_{\alpha}^{i} Z_{i}\left(x_{\alpha}\right)
$$

where $\lambda_{\alpha}^{i}$ are the cokriging weights. For the details on how to determine the weights of the resulting cokriging system the reader is referred to Wackernagel (1988) or Goovaerts (1992).

- Coregionalization model in practice: Adjusting a linear model of coregionalization to $p$ variables requires the modeling of $p(p+1) / 2$ semi-variograms being careful that $\boldsymbol{\Gamma}(h)$ remains negative semi-definite. Goulard and Voltz (1989) developed an iterative procedure for automating this process. The main steps are: (i) Decide how many spatial factors to consider, (ii) decide which are the shapes of the basic variogram functions $g_{u}(h)$, (iii) decide the parameters of these functions, (iv) determine the coefficients of the coregionalization matrices $\mathbf{B}_{u}$.

\section{Case Study - FKA applied to the ESM geochemical data set}

- Variable grouping and semi-variogram models: The analysis of the experimental semi-variograms computed for all the ESM variables identified groups of variables with similar correlation structures, suggesting that each group had a common originating process. The transition elements Fe, Co and Ni could be fitted by a semi-variogram composed by a nugget effect plus a spherical semi-variogram with a range of $2800 \mathrm{~m}$ plus a spherical semi-variogram with a range of $11000 \mathrm{~m}$; while the chalcophile elements $\mathrm{Zn}, \mathrm{Cu}, \mathrm{Pb}$, Sr could be fitted by a nugget effect plus a spherical semi-variogram with a range of $700 \mathrm{~m}$ plus a spherical semi-variogram with a range of $7000 \mathrm{~m}$. The other elements could be fitted with a the same combination of structures but with different ranges (see Table 2).

Table 2 Models used to fit the experimental semi-variograms, when each variable is considered independently. All variograms are isotropic, and the number in parenthesis is the range

\begin{tabular}{||l|l||}
\hline variables Groups & semivariograms Decomposition \\
\hline $\mathrm{Fe}, \mathrm{Co}, \mathrm{Ni}$ & nugget effect $+\mathrm{Sph}(2800 \mathrm{~m})+\mathrm{Sph}(11000 \mathrm{~m})$ \\
\hline $\mathrm{Zn}, \mathrm{Cu}, \mathrm{Pb}, \mathrm{Sr}$ & nugget effect $+\mathrm{Sph}(700 \mathrm{~m})+\mathrm{Sph}(7000 \mathrm{~m})$ \\
\hline $\mathrm{La}, \mathrm{Y}$ & nugget effect $+\mathrm{Sph}(800 \mathrm{~m})+\mathrm{Sph}(11500 \mathrm{~m})$ \\
\hline $\mathrm{Ti}$ & nugget effect $+\mathrm{Sph}(2000 \mathrm{~m})+\mathrm{Sph}(12000 \mathrm{~m})$ \\
\hline $\mathrm{pH}$ & nugget effect $+\mathrm{Sph}(3300 \mathrm{~m})+\mathrm{Sph}(12000 \mathrm{~m})$ \\
\hline $\mathrm{Ba}$ & nugget effect $+\mathrm{Sph}(1100 \mathrm{~m})+\mathrm{Sph}(8800 \mathrm{~m})$ \\
\hline
\end{tabular}

The FKA will focus on the group of almost heavy metals $\mathrm{Zn}, \mathrm{Pb}, \mathrm{Cu}$ and Sr. Strontium acting as an alternative to $\mathrm{Ca}$, when the latter cannot analyzed. The ESM carbonate rocks are home of many chalcophile vein mineralizations (Bartholomé et al. 1977). In addition, due to their frequent association to sulphide altering mineralizations, Fe, Ba, La and $\mathrm{Y}$ are also included in the analysis.

The analysis of the semi-variograms that could be fitted to the different variables (when each variable is considered independently) serves as the basis to define 
the basic functions $g_{u}(h)$ of the LMC to be used in the FKA. It is clear that three functions are to be used, a nugget effect plus two spherical (isotropic) semivariograms. The ranges of these semi-variograms as well as the coefficients of the variance-covariance matrices were determined during the fitting process of the LCM. The final ranges of the two spherical semi-variograms are set to $800 \mathrm{~m}$ and $8000 \mathrm{~m}$, slightly larger than the range values used to fit the individual variograms for $\mathrm{Zn}, \mathrm{Cu}, \mathrm{Pb}$ and $\mathrm{Sr}$. The final fits of the 36 direct and cross semi-variograms, after normalizing all variables to zero mean and unit variance, are shown in Fig. 2. The LCM provides the variance-covariance matrices $\mathbf{B}_{u}$, and from them we can
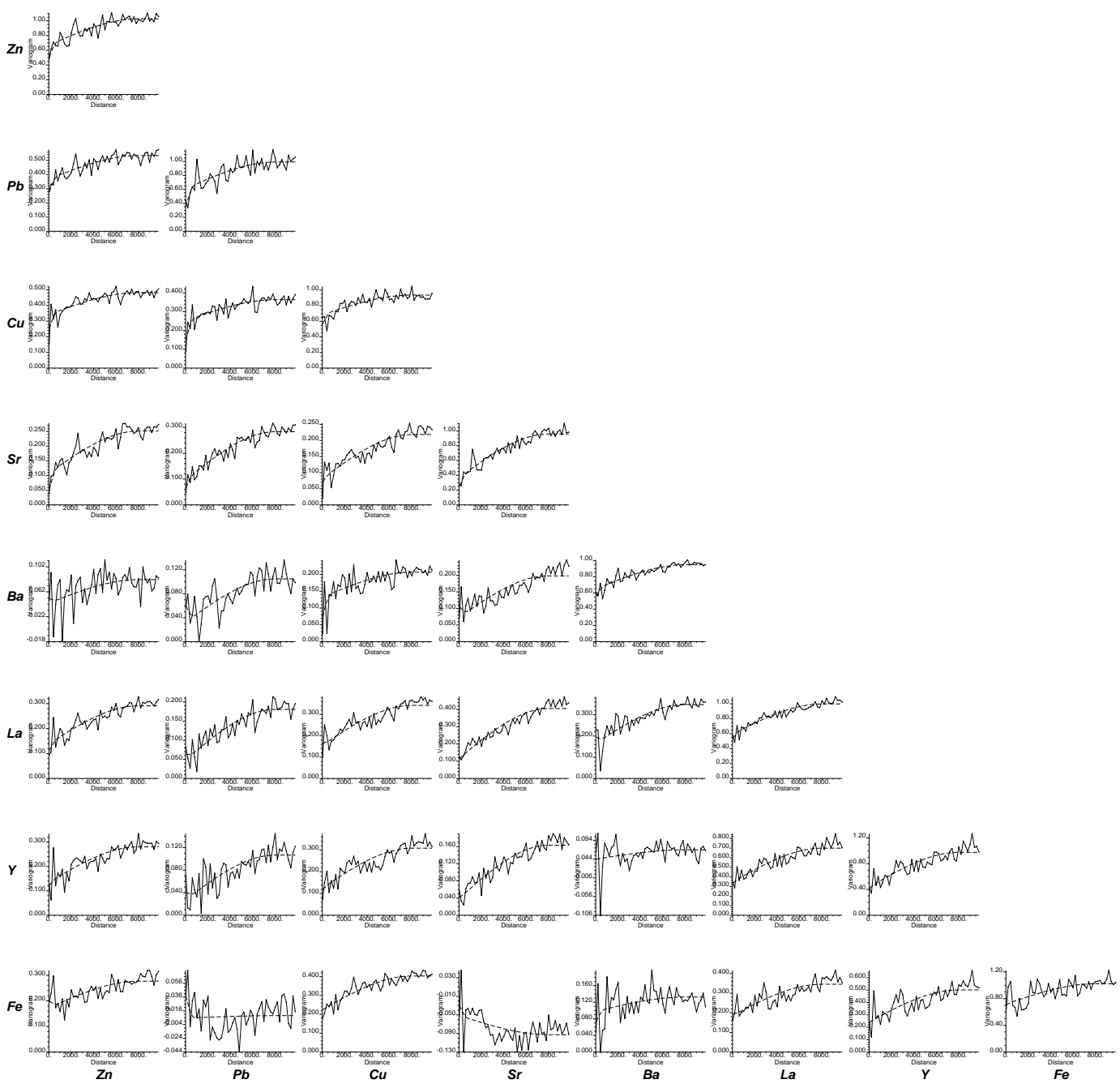

Fig. 2 Direct and cross semi-variograms of the normalized values of the variables studied. Experimental (connected dots by solid line), and LMC model fitted (dashed line)

determine the matrices $\mathbf{A}_{u}$ (Eq. 7), which contain the weights that each one of the 
spatial factors $Y_{u}^{v}$ receives in the decomposition of each variable. The correlation coefficients (Eq. 8) between these three factors and each of the variables are shown in Tables 3, 4 and 5 .

\section{Results and discussions}

To help interpreting major trends and its relationship to the underlying general lithology in the ESM area, the three coregionalized factors for each spatial scale that explain most of the variance were mapped using cokriging, and shown in Fig. 3,4 and 5 .

\subsection{Point scale interpretation}

The point scale corresponds, in fact, to distances smaller than the sampling grid, which was about $200 \mathrm{~m}$. The factorial analysis corresponding to the point scale is summarized in Table 3, which shows, for the three factors explaining most of the variance, the coefficients of correlation between the regionalized factors and the variables, and the fraction of the total variance explained by each factor. These 3 factors account for $70 \%$ of the total variance. We can notice the following:

Table 3 Decomposition of the coregionalization matrix 1 (point scale). Only the three factors that explain most of the variance are shown

\begin{tabular}{|c|c|c|c|}
\hline Correlations regionalized & factors- & iriables & $\overline{\text { int scale) }}$ \\
\hline elements & $Y_{1}^{1}$ & $Y_{2}^{1}$ & $Y_{3}^{1}$ \\
\hline $\mathrm{Zn}$ & 0.175 & 0.875 & 0.048 \\
\hline $\mathrm{Pb}$ & -0.088 & 0.783 & 0.210 \\
\hline $\mathrm{Cu}$ & 0.311 & 0.702 & 0.092 \\
\hline $\mathrm{Sr}$ & -0.016 & 0.191 & 0.552 \\
\hline $\mathrm{Ba}$ & 0.113 & 0.046 & 0.832 \\
\hline $\mathrm{La}$ & 0.676 & 0.049 & 0.579 \\
\hline $\mathrm{Y}$ & 0.786 & 0.059 & 0.206 \\
\hline $\mathrm{Fe}$ & 0.836 & 0.254 & -0.225 \\
\hline \multicolumn{4}{|c|}{ Percentage of total variance explained } \\
\hline & 27.94 & 23.94 & 18.48 \\
\hline
\end{tabular}

Factor 1 of point scale explaining 27.94\% of the total variance: This factor main correlations are with La, Y, and Fe, that is, rare earths and iron. The map of this factor (Fig. 3, top left) shows a uniform distribution of values with few peaks falling almost exclusively in the vicinity of carbonates. This reflects the dominant silicates in the ESM basin and the presence of occasional high concentrations of iron in contact with carbonate bands, what is consistent with reports on iron ore bodies known in the area (Delmer, 1912-1913). Yet, these point anomalies could also originate from mining or industrial activities from the past. In order to remove any doubt about the origin of this contamination, an in situ verification is necessary.

Factor 2 of point scale explaining 23.94\% of the total variance: This factor main correlations are with heavy metals $\mathrm{Zn}, \mathrm{Cu}$ and $\mathrm{Pb}$; at this scale, high values of this 


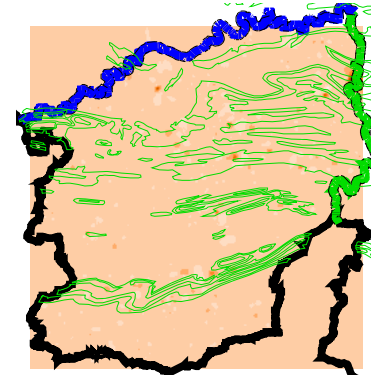

Facteur 1 (structure ponctuelle)

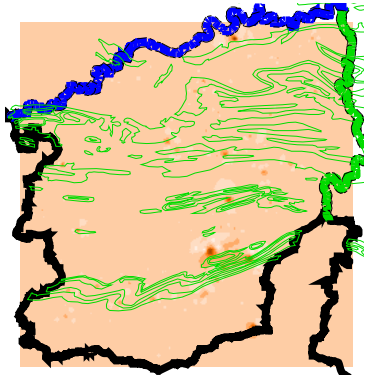

Facteur 2 (structure ponctuelle)
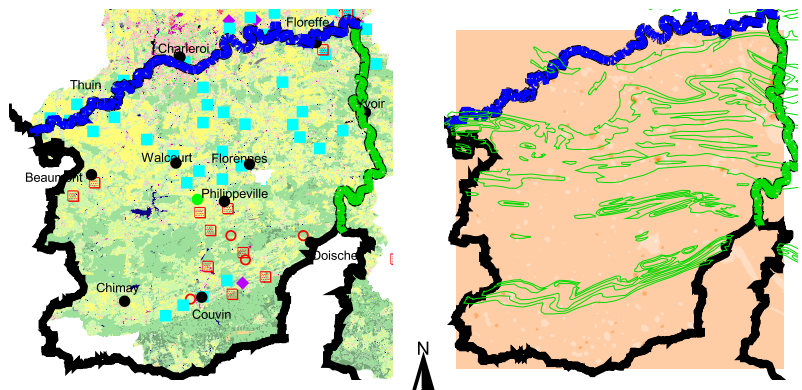

Facteur 3 (strn
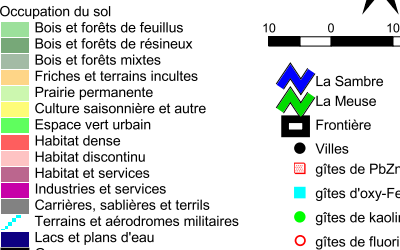

- Villes

gites de PbZn

gles doxy

gites de kaolin

- gites de baryte

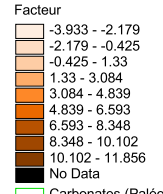

Fig. 3 Cokriging-

interpolated maps of

the 3 first coregionaliza-

tion factors associated to

the point scale, and land

use map with indication of metalliferous deposits.

factor may be explained by some contamination event. This factor map (Fig. 3, top right) shows areas of high values (dark colors) in the carbonate bands south of Philippeville. The proximity to Philippeville may indicate an anthropogenic origin. But, it could also come naturally from the known $\mathrm{Pb}-\mathrm{Zn}$ mineralizations. Again, in situ investigations are necessary. Furthermore, the orthogonality of factor 2 and factor 1 makes it clear that chalcophile anomalies have nothing to do with the oxy-hydroxides of Fe-Mn (known to be metal traps) or with iron deposits, which are the most common forms of iron in the ESM.

\subsection{Local scale $(800 \mathrm{~m})$ interpretation:}

Factor 1 of local scale explaining 43.42\% of the total variance: This factor main correlations are with the chalcophile elements $(\mathrm{Zn}, \mathrm{Pb}$ and $\mathrm{Cu})$. The map of this factor (Fig. 4, top left) shows a good correspondence between high values (dark) and carbonate horizons, particularly in the southern part of the ESM (Frasnian), where indices of $\mathrm{Pb}-\mathrm{Zn}$ mineralization were reported. It suggests that this factor corresponds to the numerous $\mathrm{Pb}-\mathrm{Zn}$ vein mineralizations reported in the ESM 
Table 4 Decomposition of the coregionalization matrix 2. Only the three factors that explain most of the variance are shown

\begin{tabular}{|c|c|c|c|}
\hline \multicolumn{4}{|c|}{ Correlations regionalized factors-variables (scale $800 \mathrm{~m}$ ) } \\
\hline elements & $Y_{1}^{2}$ & $Y_{2}^{2}$ & $Y_{3}^{2}$ \\
\hline $\mathrm{Zn}$ & 0.764 & -0.400 & 0.424 \\
\hline $\mathrm{Pb}$ & 0.741 & -0.336 & -0.577 \\
\hline $\mathrm{Cu}$ & 0.954 & 0.238 & 0.100 \\
\hline $\mathrm{Sr}$ & 0.188 & -0.684 & 0.328 \\
\hline $\mathrm{Ba}$ & 0.326 & 0.880 & 0.221 \\
\hline $\mathrm{La}$ & -0.064 & -0.394 & 0.402 \\
\hline $\mathrm{Y}$ & 0.097 & 0.045 & 0.477 \\
\hline $\mathrm{Fe}$ & -0.262 & 0.913 & 0.110 \\
\hline \multicolumn{4}{|c|}{ Percentage of total variance explained } \\
\hline & 43.42 & 24.46 & 17.59 \\
\hline
\end{tabular}

carbonates. This is supported by the correspondence between the $800 \mathrm{~m}$ scale and the average size of the metallic veins (about $1000 \mathrm{~m}$ ) observed in the region.

Factor 2 of local scale explaining 24.46\% of the total variance: This factor is highly (positively) correlated with $\mathrm{Fe}$ and $\mathrm{Ba}$, and also negatively correlated with Sr. This opposed correlation reflects the mutual exclusion of ferrous mineralizations and carbonates ( $\mathrm{Sr}$ is an alternative to $\mathrm{Ca}$ or limestone). Indeed, Delmer (1912) described iron deposits to often fill cavities of karstic dissolution in the carbonatessilicates contact. Consequently, Factor 2 of $800 \mathrm{~m}$ scale reflects the few small veins of Limonite existing in the area.

Factor 3 of local scale explaining $17.59 \%$ of the total variance: This factor is mildly correlated with La, Y, Sr, Ba and Zn. This factor may indicate an accumulation of different detrital materials, and other heavy minerals, due to the alteration of the surrounding formations.

4.3 Regional scale (8000 m) interpretation:

Table 5 Decomposition of the coregionalization matrix 3. Only the three factors that explain most of the variance are shown

\begin{tabular}{|c|c|c|c|}
\hline \multicolumn{4}{|c|}{ Correlations regionalized factors-variables (scale $8000 \mathrm{~m}$ ) } \\
\hline elements & $Y_{1}^{3}$ & $Y_{2}^{3}$ & $Y_{3}^{3}$ \\
\hline $\mathrm{Zn}$ & 0.318 & 0.052 & 0.792 \\
\hline $\mathrm{Pb}$ & -0.013 & 0.234 & 0.836 \\
\hline $\mathrm{Cu}$ & 0.601 & 0.255 & 0.433 \\
\hline $\mathrm{Sr}$ & -0.045 & 0.889 & 0.317 \\
\hline $\mathrm{Ba}$ & 0.097 & 0.573 & 0.027 \\
\hline $\mathrm{La}$ & 0.647 & 0.695 & 0.182 \\
\hline Y & 0.895 & 0.239 & 0.081 \\
\hline $\mathrm{Fe}$ & 0.876 & -0.125 & 0.089 \\
\hline \multicolumn{4}{|c|}{ Percentage of total variance explained } \\
\hline & 30.84 & 26.65 & 19.78 \\
\hline
\end{tabular}




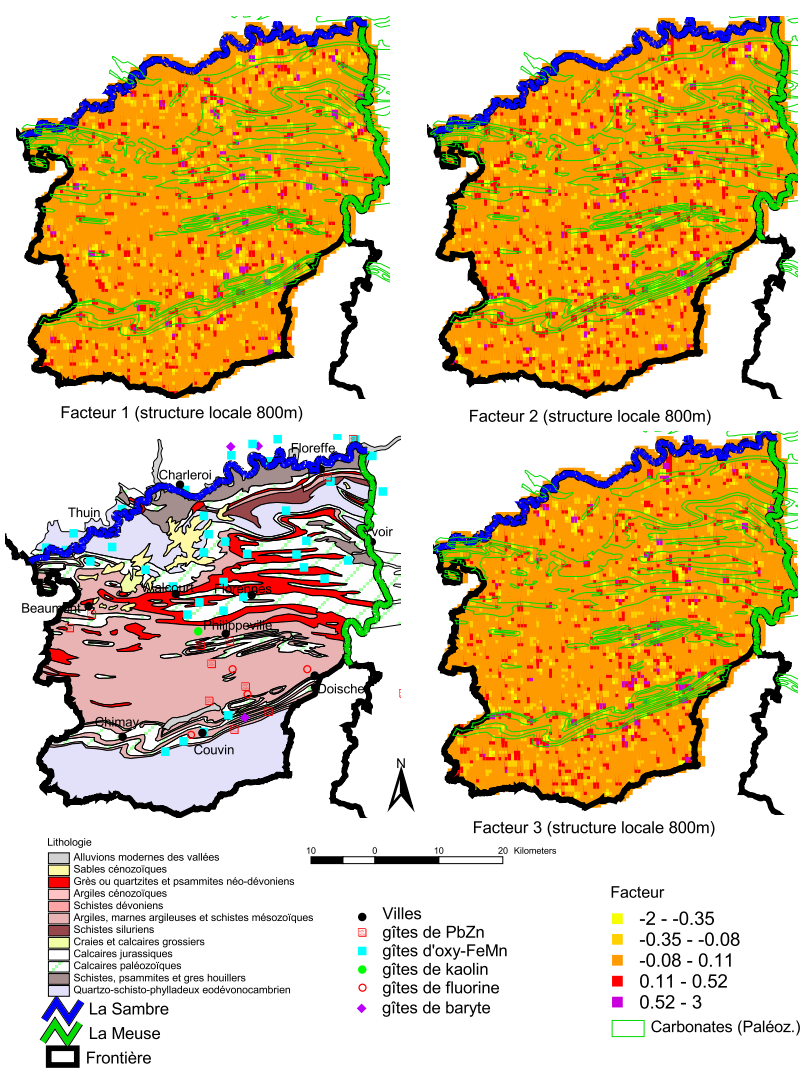

Fig. 4 Cokriging-

interpolated maps of the 3 first coregionalization factors associated to the local scale $(800 \mathrm{~m})$, and lithologies map

Factor 1 of regional scale explaining $30.84 \%$ of the total variance: This factor main correlations are with $\mathrm{Fe}, \mathrm{Y}, \mathrm{La}$ and $\mathrm{Cu}$, similar to factor 1 at the point scale. Fig. 5 (top left) shows two major areas of positive values, stretched along NE-SW; one of them is located around the triangle of Philippeville-Florennes-Walcot, and the other one S-SE of Philippeville. Comparing this map to the lithological map one can notice that these two areas coincide well with known ferrous indications in the region. Consequently, this factor 1 of the regional scale corresponds probably to large iron haloes in the area of Philippeville-Fraire-Morialmé. Because iron is a very mutable material, it is easily spread in the environment, what would explain its association with Famennian bands of terrigenous clay-schist and phyllite schist.

Factor 2 of regional scale explaining 26.65\% of the total variance: This factor is, by construction, orthogonal to the preceding factor 1 , and is best correlated to $\mathrm{Sr}, \mathrm{Ba}$ and La. The corresponding map (Fig. 5, top right) shows areas of positive correlation in the carbonates and their surroundings. This is particularly visible with the Frasnian limestone bands in the south.

Factor 3 of regional scale explaining $19.78 \%$ of the total variance: This factor main correlations are with $\mathrm{Pb}$ and $\mathrm{Zn}$, and it also displays a mild correlation with $\mathrm{Sr}$ and $\mathrm{Cu}$. This factor is marking the presence of regional $\mathrm{Pb}-\mathrm{Zn}$ mineralized zones and geochemical dispersion haloes linked to carbonates. In this factor map 


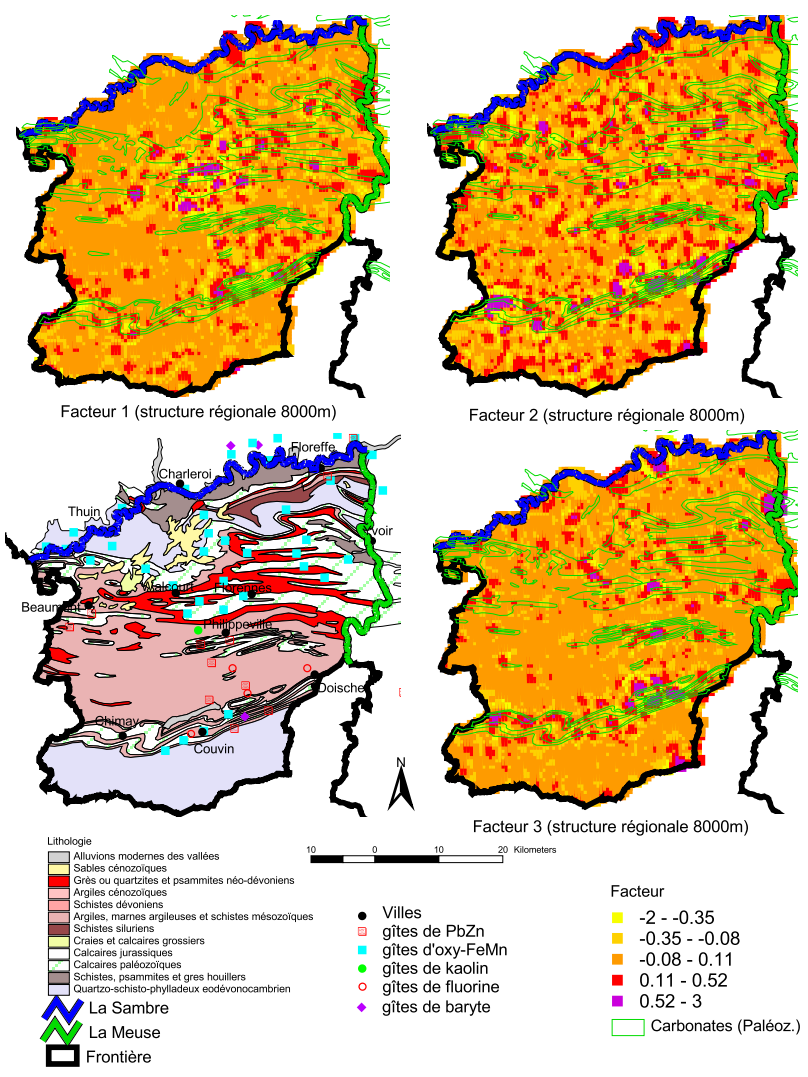

Fig. 5 Maps of the 3 first coregionalized factors cokriged, regional scale $8000 \mathrm{~m}$

(Fig. 5, bottom right) the overlap of high factor values and limestones is evident, particularly in the Frasnian bands in the southern part. This factor, also confirms a remarkable feature, that the Frasnian carbonates seem to contain more chalcophile evidence than its Devonian counterparts. This feature is very clear at this scale, but it is also noticeable at the other scales.

\section{Conclusion}

The Factorial Kriging Analysis of a fraction of the Walonian geochemical dataset showed quite interesting results for contamination remedial purposes. Three main scales of variability have been identified, a point scale (below $200 \mathrm{~m}$ ), a local scale $(800 \mathrm{~m})$ and a regional scale $(8000 \mathrm{~m})$. For each scale, two main coregionalizations were clearly noted. The first one composed of transition and detrital elements (Fe, Y, La, Ba) and the second one composed of chalcophile heavy elements ( $\mathrm{Zn}$, $\mathrm{Pb}, \mathrm{Cu}$ ). The comparison of the spatial patterns of the different factors with the underlying lithology proves that heavy metal spreading in the ESM is regionally controlled by the regional lithology and locally by numerous vein mineralizations. Meanwhile, at the point scale, the revealed chalcophile heavy metal concentrations are difficult to relate to the mineralizations and they are probably of anthropogenic 
origin. These concentrations, at the point scale identify contamination hazard areas that should be first targeted in any early checking and remediation.

\section{References}

1. Maria Astel A, Chepanova L, Simeonov V (2011), Soil Contamination Interpretation by the Use of Monitoring Data Analysis. Water, Air, and Soil Pollution, Volume 216, Issue 1-4, pp 375-390.

2. Bartholomé P, et al.(1977) Métallogénie de la Belgique, des Pays-Bas et du Luxembourg, Rapport nr 1, 38 pages, Belgium.

3. Candeias C, Ferreira da Silva E, Salgueiro A R, Pereira H G, Reis A P, Patinha C, Matos J X, Avila P H (2011) The use of multivariate statistical analysis of geochemical data for assessing the spatial distribution of soil contamination by potentially toxic elements in the Aljustrel mining area (Iberian Pyrite Belt, Portugal).

4. da Silva E F, Avila P F, Salgueiro A R, Candeias C, Pereira HG (2013) Quantitative spatial assessment of soil contamination in S. Francisco de Assis due to mining activity of the Panasqueira mine (Portugal). Environmental Science and Pollution Research.

5. Delmer A (1912), La question du minerai de fer en Belgique (première partie et deuxiéme partie), Annales des mines de Belgique, Tome XVII", 4ème livraison, 853-940, (1912), and Tome XVIII", 2ème livraison, 325-448.

6. Goovaerts P, (1997) Geostatistics for natural resources evaluation, 1st Ed., Oxford university press, 483 pages, Oxford.

7. Goovaerts P (1998) Geostatistical tools for characterizing the spatial variability of microbiological and physico-chemical soil properties. Biology and Fertility of Soils, Volume 27, Issue 4, pp 315-334.

8. Goovaerts P (1993) Spatial orthogonality of the principal components computed from coregionalized variables, Mathematical Geology, vol 25, 281-302.

9. Goovaerts P (1992) Factorial kriging analysis: a useful tool for exploring the structure of multivariate spatial soil information, Journal of Soil Science, vol 43, 597-619.

10. Goovaerts P (1991) Etude des relations entre propriétés physico-chimiques du sol par la géostatistique multivariable, Cahiers de Géostatistique, vol 1, 247-261, Compte-rendu des Journées de Géostatistique, Fontainebleau, France.

11. Guagliardi I, Buttafuoco G, Cicchella D, De Rosa R (2013) A multivariate approach for anomaly separation of potentially toxic trace elements in urban and peri-urban soils: an application in a southern Italy area. Journal of Soils and Sediments, Volume 13, Issue 1, pp $117-128$.

12. Liang-Mei Huang, Chao-Bing Deng, Ning Huang, Xiao-Jia Huang (2013) Multivariate statistical approach to identify heavy metal sources in agricultural soil around an abandoned PbZn mine in Guangxi Zhuang Autonomous Region, China. Environmental Earth Sciences, Volume 68, Issue 5, pp 1331-1348.

13. Khedhiri S, Semhi Kh, Duplay J, Darragi F (2011) Comparison of sequential extraction and principal component analysis for determination of heavy metal partitioning in sediments: the case of protected Lagoon El Kelbia (Tunisia). Environmental Earth Sciences, Volume 62, Issue 5, pp 1013-1025.

14. Keshav Krishna A, Rama Mohan K, Murthy N N, Periasamy V, Bipinkumar G, Manohar K, Srinivas Rao S (2013) Assessment of heavy metal contamination in soils around chromite mining areas, Nuggihalli, Karnataka, India. Environmental Earth Sciences,DOI: 10.1007/s12665-012-2153-6..

15. Liebens J, Mohrherr C J, Ranga Rao K (2012) Trace metal assessment in soils in a small city and its rural surroundings, Pensacola, FL, USA. Environmental Earth Sciences, Volume 65, Issue 6, pp 1781-1793.

16. Rodrguez Martn, J. Antonio, Vzquez de la Cueva A, Grau Corb, Manuel J, Lpez Arias M (2007) Factors Controlling the Spatial Variability of Copper in Topsoils of the Northeastern Region of the Iberian Peninsula, Spain. Water, Air, and Soil Pollution, Volume 186, Issue 1-4, pp 311-321.

17. Matheron G (1982) Pour une analyse krigeante des données régionalisées, Note interne N-732, Centre de Géostatistique, Fontainbleau, France.

18. Queiroz J C B et al. (2008) Geochemical characterization of heavy metal contaminated area using multivariate factorial kriging, Environmental Geology 55:95105, Srpinger-Verlag. 
19. Sondag F, Martin H (1984) Inventaire géochimique des ressources métallifères de la Wallonie. Synthèse générale et rapport de fin de recherches, UCL, 15 pages, Projet Ministère de l'économie Wallonne, Belgique.

20. Wackernagel H (1988) Geostatistical techniques for interpreting multivariate spatial information, Quantitative analysis of mineral and energy resources, EDITOR "C. F. Chung et al.", 393-409, Reidel publishing company.

21. Wackernagel H, Butenuth C(1989) Caractérisation d'anomalies géochimiques par la géostatistique multivariable, Journal of Geochemical Exploration, vol 32, 437-444.

22. Xiao H Y, Zhou W B, Zeng F P, Wu D S (2010) Water chemistry and heavy metal distribution in an AMD highly contaminated river. Environmental Earth Sciences, Volume 59, Issue 5, pp 1023-1031.

23. Ming-Sheng Yeh, Yu-Pin Lin, Liang-Cheng Chang (2006) Designing an optimal multivariate geostatistical groundwater quality monitoring network using factorial kriging and genetic algorithms. Environmental Geology, Volume 50, Issue 1, pp 101-121. 